\title{
ОСОБЕННОСТИ ПОСТРОЕНИЯ СБЫТОВОЙ ПОЛИТИКИ КОМПАНИЙ НА РОССИЙСКОМ ПРОДОВОЛЬСТВЕННОМ РЫНКЕ
}

\author{
А. А. Хныкина \\ Московский гуманитарный университет
}

\begin{abstract}
Аннотация: Одним из приоритетных направлений развития коммерческой деятельности на рынке продовольственных товаров является формирование и обеспечение функционирования сбытовой политики. Она обеспечивает доведение товара от производителя до потребителя, позволяет получить и оценить финансовую отдачу от осуществленных маркетинговых усилий.

Текст доклада автора на Общероссийской (национальной) научной конференции «Моисеевские чтения. Культура и гуманитарные проблемы современной цивилизации», которая состоялась 4-5 марта 2020 г. в Московском гуманитарном университете
\end{abstract}

Ключевые слова: сбыт; сбытовая политика; особенности сбытовой политики

\section{FEATURES OF BUILDING A SALES POLICY OF COMPANIES IN THE RUSSIAN FOOD MARKET}

\author{
A. A. Khnykina \\ Moscow University for the Humanities
}

Abstract: One of the priority directions in the development of commercial activity in the market of food products is the formation and functioning of a sales policy. It ensures that the product is delivered from the manufacturer to the consumer and allows you to get and evaluate the financial return of the marketing efforts involved.

The text of the author's speech at the All-Russian (National) Scientific Conference "Moiseev's Readings. The Culture and Humanitarian Issues of Modern Civilisation", which was held at Moscow University for the Humanities on 4-5 March, 2020.

Keywords: sales; sales policy; features of sales policy

Сбытовой политикой называют систему управления коммерческой деятельностью, которая включает в себя: совокупность сбытовых стратегий маркетинга (стратегии охвата рынка, позиционирование товара и т. п.) и комплекс мероприятий (решений и действий) по формированию ассортимента выпускаемой продукции и ценообразованию, по формированию спроса и стимулированию сбыта (реклама, обслуживание покупателей, коммерческое кредитование, скидки), заключению договоров продажи (поставки) товаров, товародвижению, транспортировке, по инкассации дебиторской задолженности, организационным, материальнотехническим и прочим аспектам сбыта» (Бурцев, 2002: 57-58).

Сбытовая политика помогает проанализировать возможные варианты поставки товаров и выделяет среди них те, которые помогают получить максимальный результат на всех участках канала, где реализуется продукция.

По сути, сбытовая политика - это совокупность мероприятий и методов, используемых фирмой в процессе распределения продукции и доведения ее до конечных потребителей.

Предприятия, которые производят продовольственные товары, огромную роль отводят сбытовой политике. Это связано с тем, что данные товары имеют высокую конкуренцию на рынке и являются товарами повседневного спроса. 
Продовольственным рынком называется система экономических отношений, которые складываются в сфере производства, транспортировки, хранения и реализации продовольствия. Особенностью данного рынка является то, что на нём осуществляются товары первой жизненной необходимости - продовольствие, содержащее важнейшее значение для деятельности человека.

Основными направлениями деятельности продовольственных предприятий в рамках сбыта являются:

1. формирование ассортиментной политики - выбор целевого рыночного сегмента, определение требований и предпочтений потребителей, разработка стратегии реализации товаров;

2. управление распределением - планирование канала сбыта (распределение), выбор типа посредников, организация и контроль работы всех участников такого канала;

3. управление товародвижением - планирование, организация и контроль процессов обработки, хранения и транспортировки груза.

Эффективная сбытовая политика предприятия зависит от влияния факторов внутренней и внешней среды, указанных на рисунке 1 (Баркан, 2004).

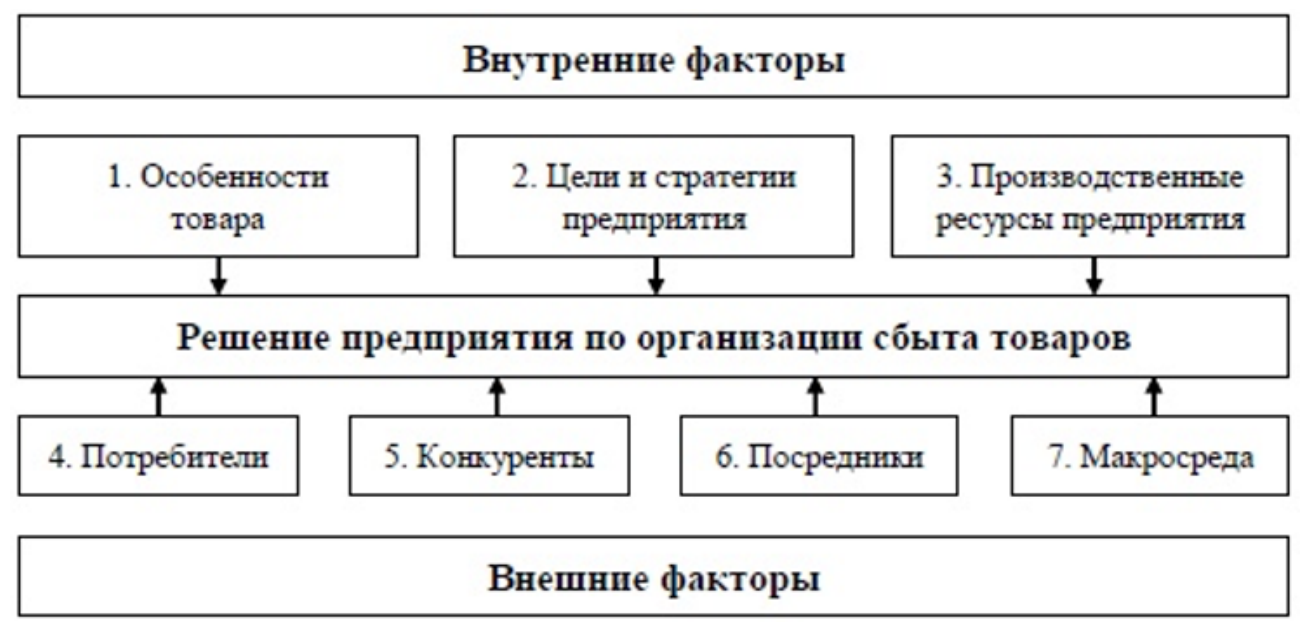

Рис. 1. Факторы, влияющие на сбытовую политику предприятия

Fig. 1. Factors influencing the sales policy of an enterprise

Если предприятие способно адаптироваться к влиянию этих факторов, то оно обеспечивает возможность производства и сбыта продовольственных товаров в должном объеме и ассортименте.

Для организации эффективного сбыта производители придерживаются следующих принципов:

- обеспечение высокой гарантированности сбыта;

- устойчивость к влиянию факторов внешней и внутренней среды;

- ориентация производства на удовлетворение потребностей рынка;

- рациональное использование собственных и заемных ресурсов;

- максимизация прибыли.

Обобщая сведения из различных публикаций, можно выделить три основных метода сбыта продукции: прямой, косвенный и комбинированный сбыт. Прямой сбыт предусматривает непосредственные отношения между производителем и 
покупателем. Прямой сбыт эффективен, если объем прямых продаж оправдывает затраты на их осуществление, либо количество потребителей невелико. При косвенном сбыте производитель продукции использует различных посредников. Использование косвенного сбыта целесообразно, когда рынок разбросан географически, либо предприятие осуществляет выход на новый рынок, либо требуются частые поставки небольших партий товаров. Комбинированный сбыт включает в себя и прямой и косвенный методы сбыта. Комбинированный сбыт часто применяется при выходе предприятия в сегменты с разными покупательскими предпочтениями.

Осуществляя коммерческую деятельность, предприниматели сталкиваются с проблемой реализации продукции. Выделяют два основных способа реализации: работа на заказ и работа на свободный рынок.

Работа на заказ предполагает, что предприятие работает на уже известный рынок. Продукция производится в соответствии с имеющимися стандартами, заключенными контрактами, соглашениями о поставках произведенной продукции и оказании услуг. Заранее оговариваются условия, сроки, объемы поставок продукции и цены.

На свободном рынке предприятие выпускает продукцию без заранее установленных барьеров. Задачи реализации товаров включают поиски новых возможных рынков сбыта, выбор конкретных форм реализации, определение оптимального уровня цен. На таком рынке реализация осуществляется через оптовую и розничную торговлю.

Рассмотрим особенности организации сбытовой политики российских компаний.

В первую очередь при сбыте товаров компания выбирает надежного и подходящего торгового посредника. Обычно компании пользуются услугами торгово-посреднических организаций (дистрибьюторов). Также если компания хочет выйти на иностранных рынок, то она использует услуги местных дистрибьюторов. И на российском и на иностранном рынке они выбираются по следующим критериям:

1) финансовые возможности и стабильность организации-дистрибьютора;

2) уровень развитости связей с потребителями (розничными или мелкооптовыми фирмами);

3) соответствие продукции компании профилю деятельности дистрибьютора (гармоничность предложения по отношению к торговому посреднику);

4) наличие соответствующего оборудования, складов и пр.;

5) уровень квалификации персонала.

Далее в работе с торговыми посредниками компании используют три вида стратегий: вталкивание, втягивание и смешанную стратегию.

Стратегия вталкивания основана на добровольном согласии посредника сотрудничать с изготовителем. Компания предлагает дистрибьютору привлекательные условия (рост продаж, расширение магазинов, реклама, повышение результативности работы сотрудников), тем самым, продвигая свой товар любыми доступными способами. Минус стратегии в том, что компания теряет контроль над 
сбытом продукции и зависит от посредника.

Стратегия втягивания направлена на конечного потребителя. При росте спроса на определенный товар или марку дистрибьюторы вынуждены закупать его и, таким образом, конечный потребитель как бы втягивает нужный ему товар в сбытовой канал.

Смешанная стратегия - интеграция двух предыдущих, т. е. воздействие и на конечного потребителя через рекламу и различные способы стимулирования продаж, и на торговых посредников, выбирая наиболее оптимальный вариант создания их заинтересованности в сотрудничестве.

Следующей особенностью на российском продовольственном рынке является сегментации распределения, т. е. компания постепенно развивает сбытовые каналы и использует различные сбытовые стратегии на национальных или региональных рынках. Сегментация проводится не только с учетом экономических критериев, но и географических (наличие гор, пустынь), плотности населения и др.

Также одной из особенностей являются скрытые затраты. Это значит, что затраты от изготовителя к потребителю варьируются в широком диапазоне. Все зависит от протяженности сбытового канала (числа посредников), эффективности работы организаций розничной торговли, наличия надлежащего складского хозяйства, логистики. Скрытые затраты возникают, если в сбытовом канале имеются мелкие оптовики, что бывает вызвано отсутствием возможности обеспечить хранение запасов. Затраты времени оптовиков увеличиваются, если розничная торговля осуществляется через большое число мелких магазинов.

Таким образом, сбытовая политика зависит от внутренних и внешних условий функционирования предприятия. Рынок предоставляет конкретному производителю различные условия и возможности для сбыта продукции. Производитель, заинтересованный в эффективности сбыта своей продукции, должен видеть и понимать реальное положение дел на рынке и только после этого принимать обоснованные решения по реализации товаров.

\section{СПИСОК ЛИТЕРАТУРЫ}

Бурцев, В. В. (2002) Совершенствование системы управления сбытом // Маркетинг в России и за рубежом. № 6. С. 57-69.

Баркан, Д. И. (2004) Управление сбытом. СПб.: СПбГУ. 344 с.

Дата поступления: 10.05.2020 г.

Хныкина Алена Анатольевна - магистрант направления подготовки «Современные маркетинговые коммуникации» Московского гуманитарного университета. Адрес: 111395, Россия, г. Москва, ул. Юности, д. 5. Тел.: +7 (905) 542-68-35. Эл. адрес: al.hnykina@yandex.ru

Khnykina Alyona Anatolyevna, Graduate Student, academic programme "Modern Marketing Communications", Moscow University for the Humanities. Postal address: 5, Yunosti St., Moscow, Russian Federation, 111395. Tel.: +7 (905) 542-68-35. E-mail: al.hnykina@yandex.ru 


\section{Для цитирования:}

Хныкина А. А. Особенности построения сбытовой политики компаний на российском продовольственном рынке // Научные труды Московского гуманитарного университета. 2020. №3. C. 48-52. DOI: https://www.doi.org/10.17805/trudy.2020.3.9 